\title{
Correspondence
}

\section{Epidurals for labour, and fainting fathers}

To the Editor:

It is routine practice for fathers to be present in the delivery room at their baby's birth. Also, it is increasingly common to have fathers present in the operating room during Caesarean section. Their presence lends support and encouragement to the mothers during labour and delivery. ${ }^{1}$ For much the same reasons and in response to consumer requests, it has been the practice of some of our anaesthetists to allow the fathers to attend their partners during establishment of labour epidurals.

The procedure is explained to the couple and the father, if electing to remain in the room, is asked to don a hat and mask and position himself beside his partner, on the side of the bed opposite the anaesthetist. A number of fathers have fainted during the procedure and it was decided to monitor the incidence prospectively.

From August, 1988 to January, 1989, 135 epidurals for labour were established, by a single anaesthetist (ETC), with partners attending. Four fathers (2.9 per cent) fainted. When interviewed after the incident, all the fathers reported that, despite an admonition not to do so, they had watched some part of the procedure. All four described a typical vaso-vagal syncopal episode. No father suffered an injury.

This incidence of fainting is similar to the reported incidence of severe paternal bradycardic episodes during Caesarean section, 2.6 per cent. ${ }^{2}$

There is one case report in the literature of a father who sustained a non-depressed skull fracture during a vagally mediated fainting episode, while attending his wife during an epidural insertion. ${ }^{3}$ We recommend that partners who wish to be present during the establishment of an epidural be specifically warned about the potential for fainting. Further, we recommend that the fathers be strongly discouraged from observing any part of the procedure, with an appropriate explanation.

We have found that the majority of the fathers tolerate the experience extremely well and that the mothers are grateful for their presence.

Edward T. Crosby BSc, MD, FRCPC

Stephen H. Halpem MD, FRCPC

Department of Anaesthesia

Women's College Hospital
University of Toronto

76 Grenville Street

Toronto, Ontario M5S 1B2

\section{REFERENCES}

1 Bradley $R$. Father's presence in the delivery room Psychosomatics 1962: 3: 474-9.

2 Shin $Y K, K$ im CH, Gadde PL. How stressful is the Cesarean section to the father? Anesth Analg 1989; 68: S258.

3 DeVore JS, Asrani R. Patemal fractured skull as a complication of obstetric anesthesia. Anesthesiology 1978; $48: 386$.

\section{Prolonged bleeding from epidural catheterization}

\section{$R E P L Y$}

We would like to reply to Dr. Ananthanarayan,' concerning prolonged bleeding from the skin puncture site during continuous epidural anaesthesia for labour and delivery. We wish to report a similar case treated with adrenaline injected subcutaneously along the epidural catheter after the delivery of the baby.

This 38-year-old Gravida III, Para II (height $155 \mathrm{~cm}$, weight $71 \mathrm{~kg}$ ), requested epidural analgesia for labour and delivery at 39 weeks' gestation. She had a history of IV heroin abuse that was treated during the last year before admission with methadone $90 \mathrm{mg} P O$, diazepam $60 \mathrm{mg}$, and aspirin with codeine 15 tablets daily. Aspirin was discontinued five days before admission. The patient smoked one and a half packs of cigarettes a day. On admission her vital signs were: $B P 120170$, $H R$ 80, $T 36.4^{\circ} \mathrm{C}$; her laboratory work was: $\mathrm{Hgb} 12.1, \mathrm{HCt} 35$, PT 11.3/12.2, PTT 30.2131.5, platelers 274,000, and bleeding time of six and a half minutes. Following a field block, a midline epidural catheter was placed on the first attempt at the $L_{3-4}$ interspace, using a 17-gauge Tuohy needle and the loss of resistance technique. Ten ml 0.25 per cent bupivacaine were administered in two doses, every two minutes, followed by an infusion of bupivacaine 0.0625 per cent with sufentanil $1 \mu \mathrm{g} \cdot \mathrm{ml}^{-1}$ at $10 \mathrm{ml} \cdot \mathrm{hr}^{-1}$ through the epidural catheter. The patient had excellent analgesia during labour and delivery. The epidural needle was inserted without difficulty and the catheter was placed without incident. Upon securing the epidural catheter, constant bleeding was noticed from the epidural site. The epidural catheter was secured and pressure was applied with a folded gauze and a wedge made of a folded sheet. This did not reduce the bleeding and she lost approximately $150 \mathrm{ml}$ of blood during two hours of labour and delivery. In the recovery room adrenaline $0.1 \mathrm{mg}$ in $1.0 \mathrm{ml}$ saline was injected 
subcutaneously using a 25-gange needle alongside the epidural catheter. The epidural catheter was removed an hour later without further complications.

We prefer to leave the epidural catheter in place during persistent bleeding from the epidural site. The catheter may tamponade the punctured vessel and help to identify the site of the traumatized vessel. We do not think it is necessary to expose the patient to new complications from reestablished epidural block.

The increase in tissue blood flow during pregnancy, ${ }^{2}$ along with the sympathetic blockade from local anaesthetic skin infiltration and field block, ${ }^{3}$ may facilitate the piercing of a blood vessel before inserting a Tuohy needle into the epidural space. We have noticed that this bleeding is self-limited except in this instance, in which prolonged bleeding was noticed despite normal coagulation function. In this patient bleeding time was normal five days after discontinuation of aspirin. In volunteers bleeding time returns to baseline by the third day after intake of $600 \mathrm{mg}^{\text {aspirin. }}{ }^{4}$

Adrenaline is a potent vasoconstrictor that is used for reduction of bleeding in a variety of surgical procedures. Systemic absorption of adrenline may reduce uteroplacental perfusion, ${ }^{5}$ and may make uterine contractions irregular. ${ }^{6}$ Therefore we recommend continuous pressure on the epidural site during labour and adrenaline injections along the epidural catheter after delivery. Should bleeding continue and labour be prolonged, a suture may be placed around the catheter as recommended by $\mathrm{Dr}$. Ananthanarayan.

Shaul Cohen MD

David Amar MD

Department of Anesthesiology

Albert Einstein College of Medicine of Yeshiva University

1300 Morris Park Avenue

New York 10461 USA

\section{REFERENCES}

1 Ananthanarayan C, Haley $S$. Prolonged bleeding from epidural insertion site. Can J Anaesth 1988; 34: 322.

2 Ginsburg J, Duncan S. Peripheral blood flow in normal pregnancy. Cardiovasc Res 1967; 1: 132.

3 Peng ALC, Behar S, Blancato LS. Reduction of postlumbar puncture backache by the use of field block

anesthesia prior to lumbar puncture. Anesthesiology 1985 63: 226-8.

4 Stuart MJ, Murphy S. Pslo FA, Evans AE, Donaldson MH Gardner $F H$. Platelet function in recipients of platelets from donors ingesting aspirin. N Engl J Med 1972; 287: $1105-9$.

5 Hood DD, Dewan DM, James FM III. Matemal and fetal effects of epinephrine in gravid ewes. Anesthesiology 1986; 64: 610-3.

6 Matadial L, Cibils LA. The effect of epidural anesthesia on uterine activity and blood pressure. Am J Obstet Gynecol 1976; 125: 846.

\section{Combined spinal-epidural needle}

\section{REPLY}

In the September 1988 issue of the Canadian Journal of Anaesthesia, Eldor and Chaimsky ${ }^{I}$ described a needle with no conduits that can be used to perform subarachnoid and epidural injection of local anaesthetics simultaneously to produce either spinal or epidural ancesthesia, respectively.

We had published earlier a very similar version of a dual needle with a similar design and for the same purpose. ${ }^{2}$ It appears that the concept has been grasped all over the world. Therefore, we expect the description of the devices and experience acquired with them will follow.

Alberto Torrieri MD

Professor, Dept. of Neurophysiology

Postgraduate Course

Argentina Association of Anesthesiology

Buenos Aires, Argentina

J. Antonio Aldrete MD, MS

Chairman, Dept. of Anesthesiology

Critical Care

Cook County Hospital

Chicago, Illinois 60612

\section{REFERENCES}

1 Eldor J, Chaimsky G. Combined spinal-epidural needle (CSEN), Can J Anaesth 1988; 35: 537-9.

2 Torrieri A, Aldrete JA. Acta Anaesth Belgica 1988; 39 : 65-6.

\section{PORCH test}

To the Editor

I read with interest Dr. Vaghadia's article on Evaluation of a postocclusive reactive circulatory hyperaemia (PORCH) test for the assessment of ulnar collateral circulation. ${ }^{1}$ I would like to outline another such test that I have not seen described in the literature.

Since the objective is to ensure adequate perfusion to the digits even with occlusion of the radial artery, a logical desirable test would involve direct measurement of the end-point. A pulse oximeter attached to one of the fingers before and after occlusion of the radial artery will achieve this. I have observed in young patients ( $<30$ years of age) that with occlusion of the radial artery with finger pressure, there is hardly a pause in the readings of the pulse oximeter, suggesting immediate and adequate collateral circulation. In other patient groups, there is sometimes a pause of from three to eight beats before the oximeter picks up a digital saturation reading again. The strength of the post-occlusion pulse reading and the actual 